lum observations. Appendix No. 5 gives the details of the results secured.

A special report on "The Eastern Oblique Are of the United States was completed and is being printed as a special publication. It is an important contribution to the subject of geodesy.

Satisfactory results have been obtained at the astronomical observatories maintained under the direction of the Survey at international expense, at Gaithersburg, Md., and Ukiah, Cal., for the purpose of determining the variation of latitude.

The Survey has been represented by its officers on commissions charged with the marking of one international and two state boundaries.

The report refers to the reorganization of the Office of Standard Weights and Measures and its establishment as the $\mathrm{Na}$ tional Bureau of Standards by act of Congress March 3, 1901. The principal reasons for the change in order to meet the present requirements of scientific and commercial interests are summarized, and a description of the functions of the new bureau and the proposed buildings and accessories is given in detail.

\section{SOIENTIFIC BOOKS.}

A Treatise on Zoology. Edited by E. RAY Lankester. Part IV. The Platyhelmia, Mesozoa, and Nemertini. By W. Blaxland Benham, D.Sc., M.A. London, Adam and Charles Black, Publishers; New York, Macmillan \& Company. Pp. 204. 114 figs. in text. Price $\$ 5.25$.

Volume IV. of Lankester's valuable series well maintains the standard set by the parts previously issued, and the lower divisions of the old group 'Vermes' are here treated in a broad and suggestive manner by a well-known helminthologist. The author deserves the gratitude of all zoologists for bringing together in a concise but comprehensive form the many facts that have been accumulated in connection with these lower forms of Invertebrata.
From the nature of the subjects treated the text is necessarily disconnected, but each division is accurately set forth in respect of the structural modifications and types, and each is complete in itself. The divisions which are thus separately treated are: Turbellaria, Temnocephaloidea, Trematoda, Cestoidea, Nemertini, and appendices to the Platyhelmia, including Rhombozoa (Dicyema, etc.), Orthonectida, Trichoplax, Salinella, etc. The author adopts Lang's classification of the Turbellaria into Rhabdocœlida, Tricladida and Polycladida; Monticelli's orders of the Trematoda, and Bürger's divisions of the Nemertini. The greatest changes are to be found in the Cestoidea. Here Lang's 'orders' Cestoda monozoa and Cestoda polyzoa are changed to the 'grades' Cestoda monozoa and Cestoda merozoa, while each is further divided into sections and orders. Among the monozoa we find the orders Amphilinacea, Gyrodactylacea and Caryophyllacea based upon the characters of the genera similarly named. The merozoa are further subdivided into sections Dibothridiata and Tetrabothridiata according to the number of sucking cups or 'bothria.' In the former there is one order, Pseudophyllidia of van Beneden, while in the latter the number of orders is raised to four: Tetraphyllidia, Diphyllidia, Tetrarhyncha of van Beneden and Tetracotylea of Diesing. (Tæniidæ auct.)

We are particularly pleased with the substitution of the term 'merozoa' for Polyzoa in the classification of Cestoidea and it should do away with the confusion of terms among English-speaking zoologists who adhere to Thompson's term Polyzoa for an order of the Molluscoida. The use of the term 'Mesozoa' in the title of the book is less satisfactory for it perpetuates the probable error of regarding a small group of parasitic and degenerate forms of Platyhelmia (?) as 'intermediate' or primitive types, notwithstanding that this view is strongly attacked in the text, where the word appears only in an historical sense.

An innovation of great value is the introduction of a concise historical statement, in which are given the names and dates of the men who have added to our knowledge of each of the classes considered; and still another 
feature which adds interest and value to the book, is the frequent allusion to general zoological theories. For example, the relations of the Nemertini to the theories of the origin of metamerism are considered in sufficient detail to make the matter clear. On this particular question the author takes no positive stand one way or the other, but is inclined, on the whole, to follow Hatschek and Mayer. These additions greatly enhance the general interest of technical works like the one under consideration and materially lessen the burden of the load of detail which the student must struggle under.

The style of writing, although somewhat heavy, is clear and definite, and awkward phrases like 'a pair of groups,' and 'than which,' or careless statements, such as 'the very close relationship of these two groups (Turbellaria and Nudibranch molluses) with the Cœlenterata' (p. 12), are rarely encountered. The author puts himself in the way of a great temptation by describing at the outset what he considers to be an 'ideal' Platyhelminth, and throughout the book we find him, consciously or unconsciously, setting up this ideal as a phylogenetic fetish. Such a method of presentation may or may not be subject to criticism, according as the book is to be used as a text-book or as a reference book. The 'type' method is very handy for teaching purposes, but as a basis for phylogenetic deductions it appears somewhat out of place and becomes a source of possible error. These are but minor criticisms, however, and may be easily overlooked when we consider the many merits and interesting suggestions which the author has embodied in this volume.

Gary N. Calkins.

\section{Columbia University.}

Yale Bi-Centennial Publications. Contributions to Mineralogy and Petrography from the Laboratories of the Sheffeld Scientific School of Yale University: Edited by S. L. Penfield and L. V. Pirsson. 1901. With three plates and several figures.

The volume comprises 'a series of reprints from some of the most important of the papers containing the results of the researches made in the chemical, mineralogical and petrographical laboratories at Yale in the lines of mineralogy and petrography.' Part I. by Professor Penfield includes a history of the mineralogical department and of the development of mineralogy at Yale, which goes back to the first years of the last century and continues since then to represent American mineralogical research. A bibliography of mineralogical papers and summary of new mineral species determined, or of formulas established, is added. Forty-three papers on mineralogical subjects are reprinted, mainly from the American Journal of Science between 1850 and 1901; the authors are S. L. Penfield, Geo. J. Brush, E. S. Dana, H. L. Wells and others. Part II. by Professor Pirsson gives a similar history and bibliography for the petrographical department, which, notwithstanding its comparatively recent organization, makes a valiant exhibit even compared with its older companion. Eight petrographic papers, several of classic interest to American petrographers, are reprinted. The volume is a valuable collection of important papers, and a striking record of original research in the departments included. JoHN E. WOLFF.

Harvard Universtity.

Velocity Diagrams. By Chas. W. MacCord, A.M., Sc.D. New York, J. Wiley \& Sons; London, Chapman \& Hall. 1901. 8vo. Pp. 113. Figs. 83. $\$ 1.50$.

Professor MacCord has published in this. form an abstract of lectures forming a part of his course of instruction, illustrating his methods of treatment of problems in kinematics involving the construction of 'velocity diagrams' and supplementing "the work embodied in his larger treatise on 'Kinematics of Practical Mechanism.' He has, for many years, found this class of graphical construction peculiarly interesting as bearing upon the work of the designing engineer planning combinations of mechanical movements, and he has developed this feature of his work with rare skill, ingenuity and practicality. The occasional appearance of an article by the same hand in the technical journals, notably in the Scientific American Supplement, has been al- 